\title{
Oligomenorrhoea and contraception despite extrauterine location of the levonorgestrel intrauterine system: a case report
}

\author{
Emmanuel Kalu, Robert Thonet
}

\section{Case report}

A 34-year-old woman attended her general practitioner for contraception 6 weeks postpartum following an unplanned pregnancy. This was her fourth pregnancy and she was determined to avoid any further pregnancy. After adequate counselling, a levonorgestrel intrauterine system (IUS) $\left(\right.$ Mirena ${ }^{\circledR}$ ) was inserted. The procedure was apparently painless and uneventful.

The benefits of the patient's new IUS were soon to be noticed as her long-standing heavy periods became light and she did not become pregnant despite regular unprotected intercourse.

The strings of the IUS had never been felt since it was inserted. Failure to identify the strings during a routine cervical smear led to further investigation with a plain Xray of the pelvis, which suggested the IUS was apparently intrauterine.

The patient's periods remained light until 4 years after IUS insertion when she presented with a 6-month history of progressively heavy and prolonged periods. It was thought that the IUS was probably due for a change. The strings could not be found during pelvic examination. A pelvic ultrasound scan identified a bright reflective echo in the lower uterine body suggestive of the site where the IUS adjoins the strings. The scan also reported a $4 \mathrm{~cm}$ simple right ovarian cyst. Careful exploration of the uterine cavity failed to yield the IUS, which was also not seen at hysteroscopy.

A subsequent laparoscopy revealed the IUS to be in the peritoneal cavity, adherent to the right ovarian fossa. A $3 \mathrm{~cm}$ simple right ovarian cyst was also noted. The IUS was retrieved laparoscopically with no difficulties (Figure 1). Bilateral tubal occlusion was performed as the patient had asked to be sterilised.

\section{Discussion}

Uterine perforation following insertion of an intrauterine contraceptive device (IUD) occurs with a frequency of 1 per 1000 insertions. ${ }^{1,2}$ The incidence of uterine perforation specific to insertion of the IUS is not known. Since its introduction in the UK in 1995, a considerable number of these devices are inserted in family planning clinics and general practice surgeries each year. Despite its uniquely designed inserter and the use of the withdrawal technique for insertion of the IUS, the incidence of uterine perforation may not be different from other IUDs. As with other IUDs, most perforations occur at the time of insertion, ${ }^{3}$ though the diagnosis may be delayed. Operator inexperience has been found to be the single most important risk factor for uterine

J Fam Plann Reprod Health Care 2005; 31(2): 163-164 (Accepted 7 January 2005)

Assisted Conception Unit, St Helier University Hospital, Carshalton, UK

Emmanuel Kalu, DFFP, MRcoG, Clinical Research Fellow

Kingston Hospital NHS Trust, Kingston-upon-Thames, UK Robert Thonet, FRCS, FRCOG, Consultant Gynaecologist

Correspondence to: Dr Emmanuel Kalu, Assisted Conception Unit, St Helier University Hospital, Wrythe Lane, Carshalton, Surrey SM5 1AA, UK. E-mail: ekalu@doctors.org.uk

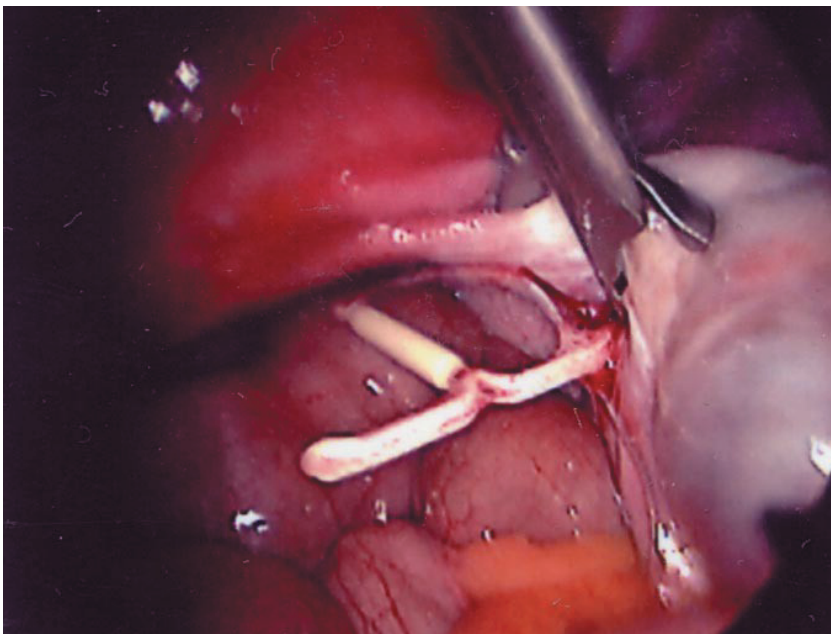

Figure 1 Laparoscopic removal of the Mirena ${ }^{\circledR}$ intrauterine system

perforation. ${ }^{1}$ Insertion of the IUD during the puerperium also carries an increase risk for perforation, especially in breastfeeding mothers. ${ }^{1}$ Abdominal pain and vaginal bleeding occurring during or shortly after insertion should alert one to the possibility of perforation. However, as highlighted by the present case, uterine perforation can be completely asymptomatic and may go unnoticed for several months or even years.

The missing IUD string must always be investigated, since it is the most frequent manifestation of the perforated device. ${ }^{3}$ Ultrasound scan and plain X-ray are the usual investigations performed with respect to missing IUDs. This case further highlights the difficulties that can be encountered in locating an extrauterine device, especially when an ultrasound scan is employed for this purpose. A plain X-ray was also unsuccessful in identifying the extrauterine location of the device in the present case.

Laparoscopic retrieval should be the preferred method when an IUD is translocated inside the abdominal cavity. ${ }^{1,4}$ However, a bioactive device such as the IUS leads to more adhesion formation and is more likely to penetrate the walls of the bowel or bladder, ${ }^{2}$ which may render laparoscopic retrieval difficult.

Despite the extrauterine location of the IUS in the present case, the patient did not become pregnant. This could, however, purely be a chance event, but the sudden change in the patient's monthly menstrual loss makes chance unlikely.

Another possibility is the long-term gradual migration of the IUS over a period of years, with complete translocation coinciding with the return of the patient's heavy periods. However, it is also possible that the IUS may have continued to be effective despite its extrauterine location.

The location of the IUS in the ovarian fossa could result in high concentrations of levonorgestrel in the vicinity of the ovaries due to local release, and high levels of levonorgestrel have been associated with anovulatory cycles..$^{5}$ The release of $20 \mu \mathrm{g}$ levonorgestrel per day in the uterine cavity is associated with very minimal systemic effects due to very low blood concentrations. Whether this 


\section{CASE REPORT/FACULTY AWARD}

applies when the IUS is located outside the uterine cavity is not known. It is possible that systemic absorption of levonorgestrel may be greater in this scenario and the Mirena IUS may continue to exert its effects in a similar way to levonorgestrel contraceptive pills and subdermal implants. It would have been interesting to know the blood level of levonorgestrel in the present case.

The outcome of this case report poses the interesting question of whether an extrauterine Mirena IUS can provide contraception.

Statements on funding and competing interests

Funding. None identified.

Competing interests. None identified.
References

1 Guillebaud J. Contraception: Your Questions Answered (3rd edn). Edinburgh, UK: Churchill Livingstone, 1999; 363.

2 Browning JJ, Bigrigg MA. Recovery of the intrauterine device from the sigmoid colon. Three case reports. Br J Obstet Gynaecol 1988; 95: 530-532.

3 Esposito JM. Perforation of the uterus secondary to insertion of IUCD. Obstet Gynecol 1966; 28: 799-805.

4 Gosh A, Ganguly G. Laparoscopic removal of perforated copper-T. Paper presented at the Third International Scientific Meeting of the Royal College of Obstetricians and Gynaecologists, New Delhi, India, March 1996.

5 Xiao BL, Zhou LY, Zhang XL, Jia MC, Luukkainen T, Allonen H. Pharmacokinetic and pharmacodynamic studies of levonorgestrelreleasing intrauterine device Contraception 1990; 41: 353-362.

\section{The 4-0-8 Sheffield Fund}

In 2001 the 4-0-8 Young People's Consultation Centre Ltd, Sheffield, UK made a significant donation to the Faculty of Family Planning and Reproductive Health Care (FFPRHC) for the purpose of funding training for health care professionals who had limited funding for attending training meetings. Any person working in the field of reproductive and sexual health care within the UK may apply. Approximately $£ 1000$ will be allocated every 3 months, either as a single award or divided between the successful applicants.

For details on how to apply to the 4-0-8 Sheffield Fund visit the Faculty website at www.ffprhc.org.uk. For an application form apply to: Chair of the Education Committee, Faculty of Family Planning and Reproductive Health Care of the RCOG, 27 Sussex Place, Regent's Park, London NW1 4RG, UK. Closing date: 6 months prior to the event for which funding is applied for.

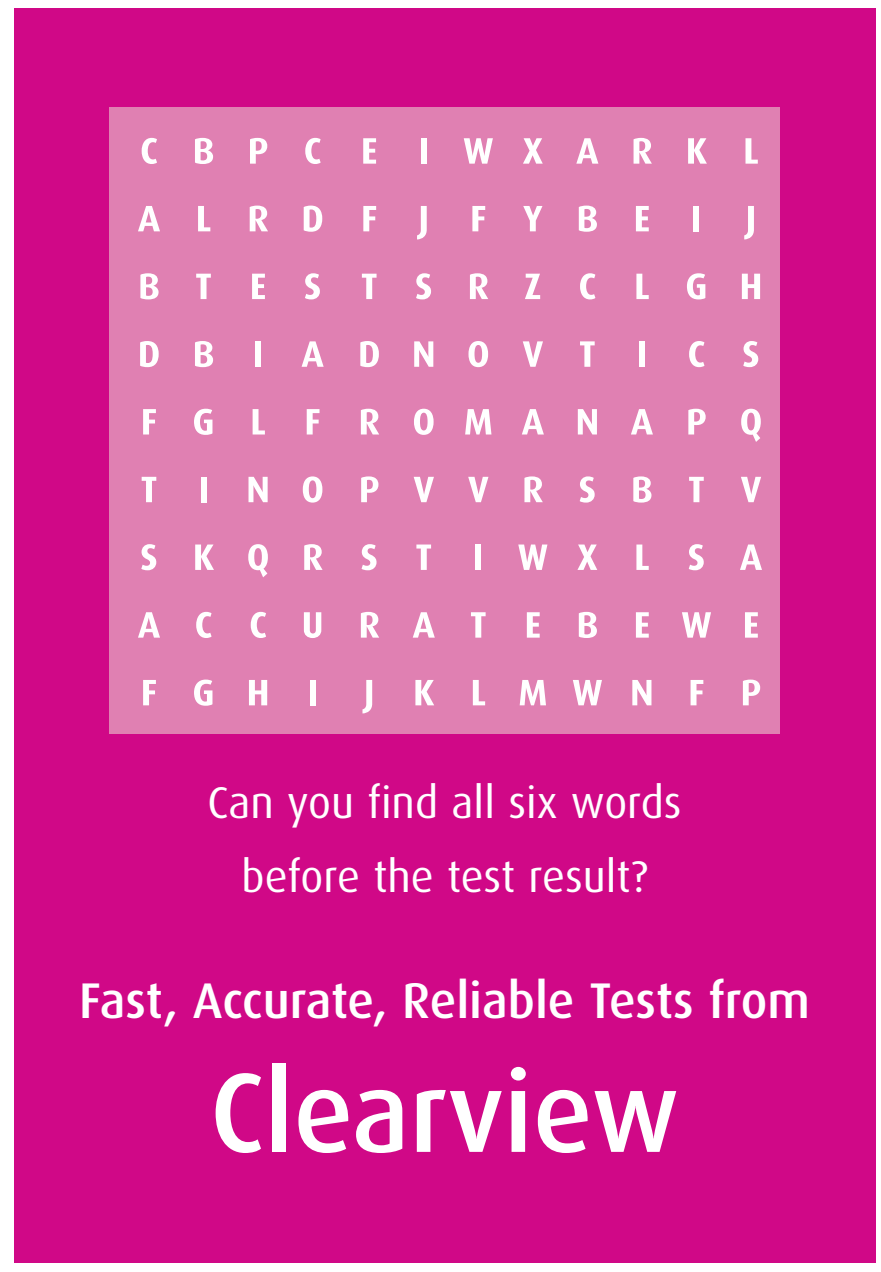

\section{It all started with pregnancy. Now we're into drugs... (amongst other things.)}

Simplicity, speed, reliability and accuracy are all key elements of professional diagnostic products. So it is with these attributes in mind that the Clearview range was developed for the healthcare field.

With a proven track record in pregnancy testing, Clearview now has a growing range of rapid, point-of-care diagnostic tests for the healthcare professional. To find out more please visit www.clearview.com

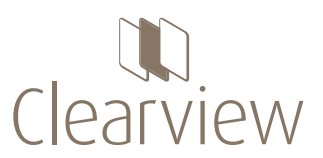

\section{Clearly different. Clearly better.}

Pregnancy • Fertility · Sexually Transmitted Disease Infectious Disease $\cdot$ Drugs of Abuse $\cdot$ Cardiovascular

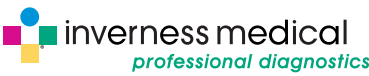

Unipath Limited, Bedford, MK44 3UP

www.clearview.com 